\title{
Frações Nitrogenadas, Glicídicas e Amônia Liberada pela Cama de Frangos de Corte em Diferentes Densidades e Tempos de Confinamento ${ }^{1}$
}

\author{
Renata Hernandes ${ }^{2}$, Jairo Osvaldo Cazetta ${ }^{3}$, Vera Maria Barbosa de Moraes ${ }^{4}$
}

\begin{abstract}
RESUMO - O presente trabalho foi conduzido com o objetivo de estudar a liberação de amônia pela cama de frangos de corte, bem como o teor de umidade e de compostos glicídicos (carboidratos redutores) e nitrogenados (nitrogênio total, nitrogênio solúvel total e nitrato) presentes na mesma, em função da densidade populacional, tempo de confinamento e sexo das aves. Realizou-se o experimento em delineamento inteiramente casualizado. A cama de frango foi submetida às densidades de 10;14; 18 e 22 aves $/ \mathrm{m}^{2} \mathrm{de} \mathrm{piso,} \mathrm{para} \mathrm{ambos}$ os sexos, e analisada em três épocas diferentes (24, 38 e 42 dias de idade das aves), utilizando-se de esquema fatorial 4x2x3 (densidades $\mathrm{x}$ sexos x épocas). De modo geral, observou-se que o sexo não influenciou o comportamento das variáveis estudadas. $\mathrm{O}$ aumento da densidade e o avanço da época de amostragem induziram a aumentos da quantidade de amônia liberada, do teor de umidade e dos teores de nitrogênio total e de nitrogênio solúvel, bem como diminuição do teor de carboidratos redutores. Estes resultados sugerem a necessidade de um controle rigoroso da amônia no ar dos galpões, principalmente em densidades elevadas e no período final de criação.
\end{abstract}

Palavras-chave: amônia, cama aviária, nitrogênio, carboidratos

\section{Nitrogenous and Glicydic Fractions and Ammonia Released by Broiler Litter in Different Stocking Densities and Periods of Breeding}

\begin{abstract}
The objective of this work was to study the ammonia released, levels of moisture, glicydic compounds (reducing sugars) and nitrogenous fractions (N-total, N-soluble, N-nitrate) of broiler litter submitted to different stocking densities (10; 14; 18 and 22 broiler per $\mathrm{m}^{2}$ ), both sex, and three breeding periods (24, 38 and 42 days). The experiment was carried out in a random design and analysed as a $4 \times 2 \times 3$ factorial. In general the sex did not affect the studied variables. The amounts of released ammonia, moisture, $\mathrm{N}$-total, and $\mathrm{N}$-soluble enhanced with the increase of density and confining time of the broiler, but the levels of reducing sugar decreased. These results show the need of ammonia monitoring and control, mainly at high densities and at the end of breeding period.
\end{abstract}

Key Words: ammonia, broiler litter, nitrogenous

\section{Introdução}

A cama para aviários deve ter a função de absorção da umidade, diluição de uratos e fezes, isolamento térmico, além de proporcionar uma superfície macia para as aves, evitando a formação de calo no peito. Esta pode constituir-se de diversos materiais, como casca de arroz, casca de amendoim, maravalha de madeira, papel e outros, devendo ser manejada adequadamente para controlar o nível de umidade, a produção de pó e amônia, exposição a agentes transmissores de doenças e prevenir a proliferação de insetos.

Vários fatores podem afetar a composição da cama aviária, tais como tipo ou composição da ração, natureza e quantidade do material de cobertura do piso do galpão, período de permanência das aves sobre o material, número de aves por área, condições e período de estocagem (Rodriguez \& Campos, 1979; citados por Oliveira et al., 1988), temperatura ambiente e utilização de equipamentos de resfriamento, como nebulizadores e ventiladores, entre outros.

Comparando sistemas de criação de frangos sobre cama e sobre malha durante um período de 8 semanas, Madelin \& Wathes (1989) mostraram que as concentrações de poeira respirável (partículas menores que $10 \mathrm{~mm}$ de diâmetro) e número de microorganismos presentes no ar foram significativamente maiores nos criatórios que utilizavam cama. $\mathrm{O}$ tipo da cama não teve efeito sobre as concentrações de amônia, nem tampouco na taxa de mortalidade das aves. Parkhurst et al. (1987) também observaram que não houve influência entre lasca de madeira, serragem e papel, mas a casca de amendoim causou pior desempenho das aves.

\footnotetext{
${ }^{1}$ Trabalho desenvolvido com bolsa de pesquisa financiada pela FAPESP.

2 Zootecnista. Estudante de doutorado do DZO - UFV. E.mail: rehernan@bol.com.br

${ }^{3}$ Eng. Agrônomo, Professor Adjunto do Departamento de Tecnologia da FCAV/UNESP. Via de Acesso Prof. Paulo Donato Castellani, s/n, CEP: 14884-900, Jaboticabal-SP. E.mail: cazetta@fcav.unesp.br

${ }^{4}$ Zootecnista, Professora do Departamento de Zootecnia da FCAV/UNESP. E.mail: vbmoraes@fcav.unesp.br
} 
A volatilização da amônia está relacionada com a umidade da cama e foi comprovado por Weaver Jr. \& Meijerhof (1991) em um experimento com diferentes umidades relativas do ar e circulação interna do ar, onde observaram que o peso corporal foi significativamente maior aos 42 dias de idade das aves expostas a baixa umidade relativa (45\%), comparada com umidades de $75 \%$ e $80 \%$. Ainda, a ordem dos aumentos dos níveis de amônia correspondeu a aumentos na umidade relativa.

Cabrera \& Chiang (1994) observaram que as perdas de amônia por volatilização variaram de 32 a $139 \%$ do amônio $\left(\mathrm{NH}_{4}{ }^{+}\right)$inicial e verificaram que este aumentava com o aumento da quantidade de água presente na cama estocada; então, os autores sugeriram que a cama seja estocada em lugar seco para diminuir perdas de nitrogênio.

O aumento da lotação de criação aumenta o teor de umidade da cama aviária (Hartung, 1955; Moreng et al., 1961; Stanley \& Krueger, 1981; Graças et al., 1990). Como o teor de umidade está relacionado com a quantidade de amônia liberada, pode-se concluir que, aumentando a densidade populacional, aumentase a volatilização da amônia.

O nível de proteína bruta ( $\mathrm{N}$ total x 6,25) na excreta das aves aumenta com a idade das aves (Kubena et al., 1973). Segundo os autores, este é um reflexo da redução da eficiência alimentar com o aumento da idade das aves, contribuindo para o aumento no teor de nitrogênio disponível na cama de frango. Experimentos realizados por Smacchia et al. (1984) demonstraram que as perdas totais de uréia e amônia originadas da cama aviária incubada a $40^{\circ} \mathrm{C}$, por 65 dias, foram maiores nas camas dos frangos mais velhos do que nas camas dos frangos jovens. Um regime alimentar acompanhado para requerimentos individuais das aves poderia reduzir a emissão de amônia (Belyavin, 1992).

Pelo exposto acima, pode-se verificar que existem fatores que diminuem ou aumentam a quantidade de amônia presente no ar ambiente dos galpões. O melhor conhecimento destes possibilitaria a adoção de um manejo mais adequado da cama para se conseguir maior produtividade de frangos de corte. Portanto, o presente trabalho teve como objetivo estudar a liberação de amônia pela cama de frangos de corte, bem como o teor de umidade e de compostos glicídicos (carboidratos redutores) e nitrogenados (nitrogênio total, nitrogênio solúvel total e nitrato) presentes na mesma, em função da densidade populacional, tempo de confinamento e sexo das aves.

\section{Material e Métodos}

O experimento foi realizado na FCAV/UNESP, campus de Jaboticabal-SP, no qual foram utilizados 4432 pintos sexados, de um dia de idade, da marca comercial "Hubbard" (2216 pintos de cada sexo), vacinados contra Bouba Aviária e mal de Marek, no incubatório. O experimento constou de oito tratamentos (dois sexos submetidos a quatro densidades populacionais: $10 ; 14 ; 18$ e 22 aves $/ \mathrm{m}^{2}$ ) e quatro repetições, em um delineamento inteiramente casualizado. O experimento teve início no verão, sendo realizado no período de 14 de janeiro a 25 de fevereiro, em que a temperatura ambiente variou de um mínimo absoluto de $20,0^{\circ} \mathrm{C}$ a um máximo de $38,0^{\circ} \mathrm{C}$, com média de $28,7^{\circ} \mathrm{C}$.

O galpão utilizado era de alvenaria, sem lanternim, com pé-direito de 3,0 m e coberto por telhas de fibrocimento. O piso das instalações era de concreto e a mureta lateral de alvenaria, com 0,6 m de altura, completada com tela de arame até o telhado. O cortinado móvel externo do galão era de plástico trançado, montado em sistema de catraca. O galpão dispunha de três ventiladores para circulação de ar. Ração e água foram fornecidos à vontade.

A cama dos frangos utilizada no experimento foi composta de maravalha de madeira, que foi submetida às determinações químicas aos 24, 38 e 42 dias de idade das aves. Para isso, foram coletadas no mínimo duas sub-amostras por $\mathrm{m}^{2}$, evitando-se ao redor dos comedouros e bebedouros. As sub-amostras foram misturadas e homogeneizadas para compor a amostra a ser submetida às diferentes avaliações.

Determinação da amônia liberada pela cama dos frangos

Em frascos de $500 \mathrm{~cm}^{3}$, foram colocados 70 gramas de cama juntamente com um béquer contendo ácido bórico $2 \%(\mathrm{~m} / \mathrm{v})$ e indicadores, sendo a seguir tampado. $O$ frasco incubador foi mantido em incubação por 16 horas, a uma temperatura constante de $30^{\circ} \mathrm{C}$. A solução fixadora de amônia foi titulada com ácido sulfúrico $0,05 \mathrm{~N}$ (Hernandes \& Cazetta, 2001).

Determinação do teor de umidade da cama dos frangos

O teor de umidade da cama foi determinado pesando-se uma quantidade de 70 gramas de cada amostra da parcela, e levando-se à estufa por 24 horas, a $50^{\circ} \mathrm{C}$. Em seguida, o material foi resfriado em 
temperatura ambiente e pesado, obtendo-se por diferença a umidade (AOAC,1970).

Determinação do teor de nitrogênio total da cama dos frangos

$O$ teor de nitrogênio total foi determinado a partir da amostra seca e moída ( 0,1 grama do material) à qual se adicionaram $5 \mathrm{~cm}^{3}$ de uma mistura de ácido sulfúrico concentrado com ácido salicílico na proporção $5: 1(\mathrm{v} / \mathrm{v})$ e também uma mistura digestora (5 gramas de sulfato de cobre, 1 grama de selenito de sódio e 76,71 gramas de sulfato de sódio). Após a digestão, o material foi transferido para o destilador de Kjeldhal e, em seguida, titulado com solução padronizada de ácido sulfúrico $0,05 \mathrm{~N}$.

Determinação do teor de nitrogênio solúvel total da cama dos frangos

Para a determinação do teor de nitrogênio solúvel total, foi feito inicialmente o extrato a partir de 0,2 grama de amostra previamente seca e moída, a qual foi colocada num erlenmayer de $50 \mathrm{~cm}^{3}$ contendo $20 \mathrm{~cm}^{3}$ de solução hidroalcoólica $80 \%(\mathrm{v} / \mathrm{v})$ e aquecida durante 15 minutos, tampada com papel alumínio. Após este tempo, o material foi filtrado e transferido para um balão volumétrico de $100 \mathrm{~cm}^{3}$. Desse extrato, retirou-se uma alíquota de $20 \mathrm{~cm}^{3}$ e procedeu-se da mesma maneira que para o nitrogênio total, exceto que se usou o ácido sulfúrico $0,002 \mathrm{~N}$ no lugar do ácido sulfúrico $0,05 \mathrm{~N}$ para titular as amostras (Faleiros et al., 1988).

Determinação do teor de nitrato da cama dos frangos

A preparação do extrato foi realizada seguindo as indicações de Ligero et al. (1987) e consistiu em utilizar 0,1 grama da amostra de cama aviária, previamente seca e moída, à qual se adicionaram $2,0 \mathrm{~cm}^{3}$ de etanol $80 \%(\mathrm{v} / \mathrm{v})$, obtendo-se, assim, o extrato que foi utilizado para a determinação do nitrato e carboidratos redutores.

Para a análise do nitrato presente na cama aviária, foram colocados $0,5 \mathrm{~cm}^{3}$ de extrato em tubos de ensaio e $0,160 \mathrm{~cm}^{3}$ de ácido salić́lico $5 \%(\mathrm{v} / \mathrm{v}) \mathrm{em}$ ácido sulfúrico concentrado, agitando-se vigorosamente e deixando-se em repouso por 20 minutos. Após este descanso, adicionaram-se $3,79 \mathrm{~cm}^{3}$ de soda cáustica $2 \mathrm{~N}$, deixando-se esfriar à temperatura ambiente. A seguir, foi realizada a leitura da absorbância em espectofotômetro a 410 nm (Cataldo et al., 1975), e o teor de nitrato foi obtido pela comparação da absorbância da amostra com a de uma curva-padrão preparada de forma semelhante às amostras.

Determinação do teor de carboidratos redutores da cama dos frangos

Inicialmente, preparou-se a solução de DNSA (ácido 3,5-dinitrossalicílico), no qual se pesaram um grama de DNSA, $20 \mathrm{~cm}^{3}$ de $\mathrm{NaOH} 2 \mathrm{~N}$ e $10 \mathrm{~cm}^{3}$ de água destilada. Em seguida, foram adicionados 30 gramas de tartarato duplo de sódio e potássio, segundo Miller (1959). A determinação do extrato foi realizada de acordo com o descrito para o teor de nitrato. Para a determinação, foram usados: $0,5 \mathrm{~cm}^{3}$ de extrato e $0,3 \mathrm{~cm}^{3}$ de solução de DNSA, colocados a fervura por 15 minutos e, em seguida, adicionados $2,2 \mathrm{~cm}^{3}$ de água destilada. Os cálculos para a obtenção do teor de carboidratos nas amostras foram baseados na comparação da absorbância das amostras com a de uma curva-padrão de glicose preparada de forma semelhante às amostras.

\section{Análise estatística}

As diferentes variáveis foram analisadas em esquema fatorial $4 \times 2 \times 3$, cujos fatores foram: densidade $\left(10 ; 14 ; 18\right.$ e 22 aves $\left./ \mathrm{m}^{2}\right)$, sexo e tempo de confinamento (idade dos frangos) em que as amostras de cama aviária foram coletadas $(24,38$ e 42 dias), com quatro repetições por tratamento. Tanto a densidade quanto a idade foram analisadas por meio de regressão polinomial, utilizando-se do método de Quadrados Mínimos.

\section{Resultados e Discussão}

Na Tabela 1, pode ser observado o resultado da análise de variância para as características avaliadas.

Conforme pode ser observado, para a amônia liberada pela cama aviária, houve efeito significativo da interação densidade de criação e idade das aves (tempo de confinamento). Isto significa que não houve um efeito semelhante da densidade sobre a quantidade de amônia liberada pela cama aviária nas diferentes épocas de amostragem da cama. O desdobramento desta interação mostrou ter havido um efeito linear significativo $(\mathrm{P}<0,05)$ das diferentes densidades para as amostras de cama coletadas aos 24 dias de idade das aves $(\mathrm{Y}=-1,376+0,160 \times$ dens $)$. Portanto, espera-se que, aos 24 dias de idade, o aumento de uma ave por $\mathrm{m}^{2}$ resulte em aumento da quantidade de amônia liberada pela cama de frango da ordem de $0,16 \mathrm{mg} / 100 \mathrm{~g}$ de cama. Já para as demais

R. Bras. Zootec., v.31, n.4, p.1795-1802, 2002 
Tabela 1 - Resumo da análise de variância para as características avaliadas na cama aviária Table 1 - Summary of variance analysis for the traits evaluated in the avian litter

\begin{tabular}{|c|c|c|c|c|c|c|c|}
\hline \multirow[b]{2}{*}{$\begin{array}{l}\text { Fontes de variação } \\
\text { Sources of variation }\end{array}$} & \multirow[b]{2}{*}{$\begin{array}{l}\text { GL } \\
D F\end{array}$} & \multicolumn{6}{|c|}{$\begin{array}{l}\text { Quadrado médio } \\
\text { Mean square }\end{array}$} \\
\hline & & $\begin{array}{l}\text { Amônia } \\
\text { liberada } \\
\text { Released } \\
\text { ammonia }\end{array}$ & $\begin{array}{l}\text { Umidade } \\
\text { Moisture }\end{array}$ & $\begin{array}{l}\text { Nitrogênio } \\
\text { total } \\
\text { Total } N\end{array}$ & $\begin{array}{l}\text { Nitrogênio } \\
\text { solúvel } \\
\text { Soluble } N\end{array}$ & $\begin{array}{l}\text { Nitrato } \\
\text { Nitrate }\end{array}$ & $\begin{array}{l}\text { Carboidratos } \\
\text { redutores } \\
\text { Reduced } \\
\text { sugar }\end{array}$ \\
\hline $\begin{array}{l}\text { Densidade } \\
\text { Density }\end{array}$ & & & & & & & \\
\hline $\begin{array}{l}\text { Reg. linear } \\
\text { Linear reg. }\end{array}$ & 1 & $60,209 * *$ & $1574,805^{* *}$ & $0,788^{*}$ & $0,0006^{\mathrm{NS}}$ & $1276,008 * *$ & $2,090 * *$ \\
\hline $\begin{array}{l}\text { Reg. quadrática } \\
\text { Squared reg. } \\
\text { Idade } \\
\text { Age }\end{array}$ & 2 & $31,954 * *$ & $805,616^{* *}$ & $0,417^{\mathrm{NS}}$ & $0,005^{\mathrm{NS}}$ & $1179,123 * *$ & $1,089 * *$ \\
\hline $\begin{array}{l}\text { Reg. linear } \\
\text { Linear reg. }\end{array}$ & 1 & $189,063 * *$ & $1326,177^{*}$ & $0,009^{\mathrm{NS}}$ & $0,0460 * *$ & $860,520^{*}$ & $7,252 * *$ \\
\hline $\begin{array}{l}\text { Reg. quadrática } \\
\text { Squared reg. }\end{array}$ & 2 & $96,716^{* *}$ & $675,166^{* *}$ & $0,027^{\mathrm{NS}}$ & $0,0829 *$ & $556,083^{*}$ & $7,991 * *$ \\
\hline $\begin{array}{l}\text { Sexo } \\
\text { Sex }\end{array}$ & 1 & $0,033^{\mathrm{NS}}$ & $124,976^{*}$ & $0,004^{\mathrm{NS}}$ & $0,0007^{\mathrm{NS}}$ & $67,933^{\mathrm{NS}}$ & $0,110^{* *}$ \\
\hline $\begin{array}{l}\text { Densidade } \mathrm{x} \text { Idade } \\
\text { Density } x \text { Age }\end{array}$ & 6 & $7,065^{*}$ & $27,889^{\mathrm{NS}}$ & $0,253^{\mathrm{NS}}$ & $0,0003^{\mathrm{NS}}$ & $317,702^{\mathrm{NS}}$ & $0,234 * *$ \\
\hline $\begin{array}{l}\text { Densidade } \mathrm{x} \text { Sexo } \\
\text { Density } x \text { Sex }\end{array}$ & 3 & $4,371^{\mathrm{NS}}$ & $22,534^{\mathrm{NS}}$ & $0,180^{\mathrm{NS}}$ & $0,0009^{\mathrm{NS}}$ & $3197,012 * *$ & $0,048 *$ \\
\hline $\begin{array}{l}\text { Sexo x Idade } \\
\text { Sexx Age }\end{array}$ & 2 & $1,125^{\mathrm{NS}}$ & $19,676^{\mathrm{NS}}$ & $0,010^{\mathrm{NS}}$ & $0,0022^{\mathrm{NS}}$ & $9,286^{\mathrm{NS}}$ & $0,009^{\mathrm{NS}}$ \\
\hline $\begin{array}{l}\text { Resíduo } \\
\text { Residual }\end{array}$ & 78 & 2,701 & 19,073 & 0,134 & 0,0018 & 174,033 & 0,016 \\
\hline $\begin{array}{l}\text { Total } \\
\text { Total }\end{array}$ & 95 & & & & & & \\
\hline
\end{tabular}

idades de coleta ( 38 e 42 dias de idade), não se verificaram efeitos linear e quadrático significativos de densidade sobre a liberação de amônia pela cama aviária. O comportamento do efeito da densidade nas diferentes idades sobre a quantidade de amônia liberada pela cama pode ser observado na Figura 1.

Verifica-se um efeito bastante acentuado da densidade no final do período de criação (42 dias), com menor liberação de amônia pela cama nas densidades mais baixas ( 10 e 14 aves $/ \mathrm{m}^{2}$ ) e um aumento bastante grande nas mais altas $\left(18\right.$ e 22 aves $\left./ \mathrm{m}^{2}\right)$. Este efeito era esperado, já que a maior densidade acarreta maior produção de excretas e aumento da umidade, sendo indesejável para a criação de frangos de corte, visto que a amônia causa inúmeros danos sobre a produtividade das aves (Attar \& Brake, 1989; Johnson et al., 1991). Já as amostras coletadas aos 38 dias praticamente não foram influenciadas pela quantidade de animais na baia.

Para a umidade liberada pela cama aviária, veri-

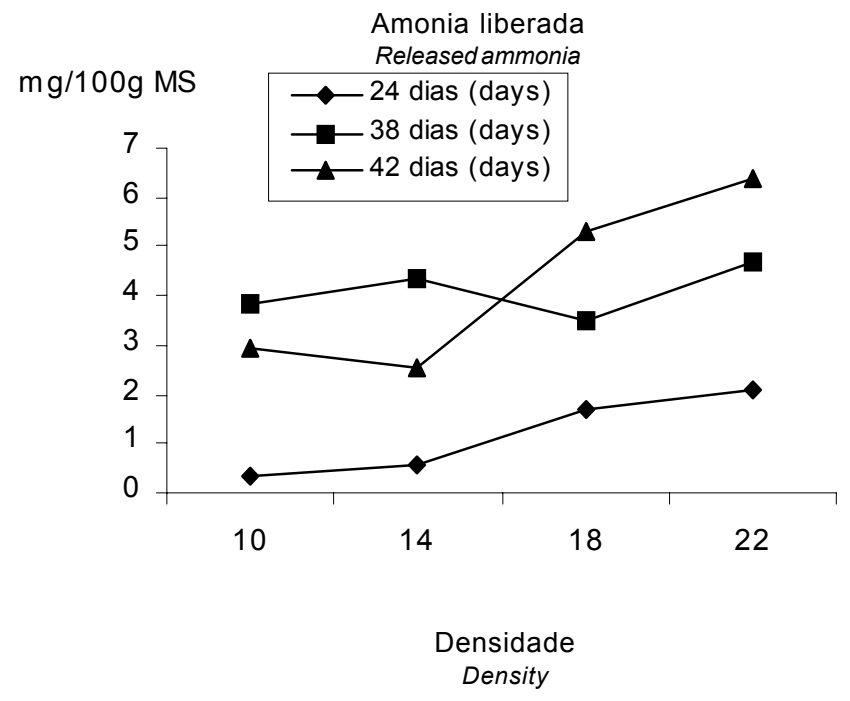

Figura 1 - Quantidades de amônia liberada pela cama de frango, em diferentes épocas de coleta e densidades de criação.

Figure 1 - Amount of ammonia released by broiler litter in different periods of breeding and stocking densities.

R. Bras. Zootec., v.31, n.4, p.1795-1802, 2002 
ficaram-se efeitos quadráticos significativos $(\mathrm{P}<0,01)$ de densidade $\left(\mathrm{Y}=5,431+2,137 \times\right.$ dens. $-0,038 \times$ dens. $\left.^{2}\right)$ e de idade $\left(\mathrm{y}=32,078-0,815 \times \mathrm{id}+0,020 \mathrm{id}^{2}\right)$. Para ambos os efeitos, o coeficiente de regressão quadrático foi de magnitude bastante pequena, sugerindo a captação pela análise de uma pequena curvatura entre os níveis estudados e, conseqüentemente, um aumento não linear da umidade com o aumento na densidade de criação. Estes resultados concordam com os apresentados por Stanley \& Krueger (1981) e Graças et al. (1990), segundo os quais, o aumento da lotação geralmente aumenta o teor de umidade da cama aviária. Nas Figuras 2 e 3, podem ser visualizados os efeitos de densidade e idade, respectivamente, sobre a umidade.

O sexo também influenciou significativamente $(\mathrm{P}<0,05)$ a umidade liberada pela cama aviária. $\mathrm{Na}$ Tabela 2, pode ser observado o resultado do teste de Tukey para os animais machos e fêmeas. Na literatura consultada, não foram observados relatos de teores diferentes de umidade na cama utilizada por frangos de corte machos e fêmeas.

Os compostos nitrogenados e glicídicos são fatores relacionados à quantidade de amônia liberada pela cama aviária, sendo utilizados ou produzidos nos processos físico-químicos e bacteriológicos que se desenvolvem na cama de frango na presença de excretas e umidade, durante o período de criação. Portanto, o seu monitoramento permite melhor enten-

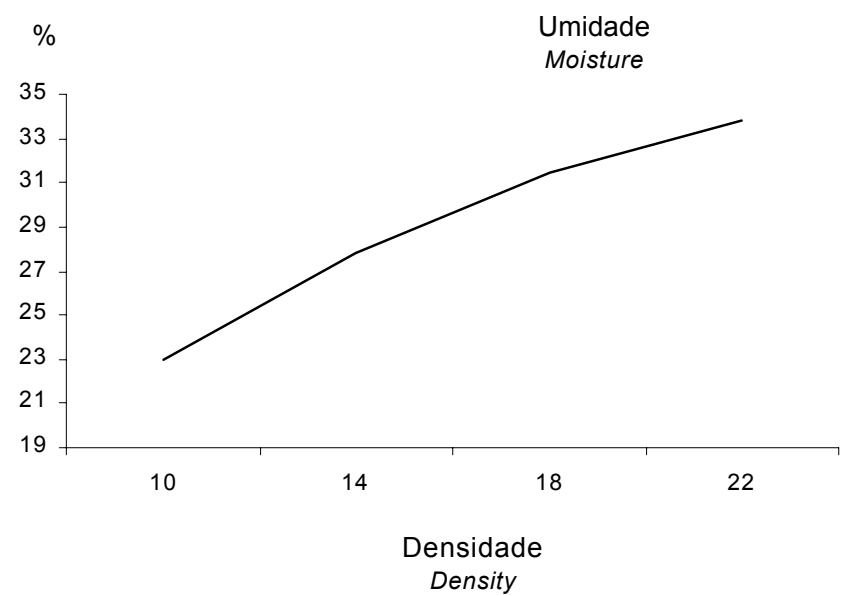

Figura 2 - Teor de umidade da cama de frango, em diferentes densidades de criação.

Figure 2 - Moisture content of broiler litter in different stocking densities.

R. Bras. Zootec., v.31, n.4, p.1795-1802, 2002
Tabela 2 - Teor médio de umidade presente na cama dos frangos (valores em \%)

Table 2 - Average moisture content in the broiler litter (values in \%)

\begin{tabular}{lc}
\hline Sexo & $\begin{array}{c}\text { Teor médio de umidade } \\
\text { Average }\end{array}$ \\
Sex & $27,86^{\mathrm{A}}$ \\
\hline Fêmea & $30,14^{\mathrm{B}}$ \\
Female & \\
Macho & \\
Male &
\end{tabular}

Médias, na coluna, seguidas de letras diferentes, diferem $(P<0,05)$ pelo teste de Tukey.

Means in the column followed by different letters differ $(P<.05)$ by Tukey test.

dimento dessas reações que ocorrem na cama, durante o período de criação dos frangos.

Para o teor de nitrogênio total nas amostras de cama, verificou-se significância apenas para o efeito linear $(\mathrm{P}<0,05)$ de densidade $(\mathrm{Y}=2,112+0,020 \times$ dens $)$, sugerindo aumento gradativo do teor de nitrogênio total liberado pelas amostras de cama, à medida que se aumenta a densidade de criação (aumento de $0,020 \mathrm{~g}$ de nitrogênio total com o aumento de uma ave por $\mathrm{m}^{2}$ ) (Figura 4). Tal aumento pode ter sido devido ao acúmulo de excreta com o tempo (Smacchia et al., 1984) e ao aumento do teor de nitrogênio na excreta das aves mais velhas (Kubena et al., 1973).

Já para o teor de nitrogênio solúvel, não se verificou efeito significativo de densidade, mas sim efeito

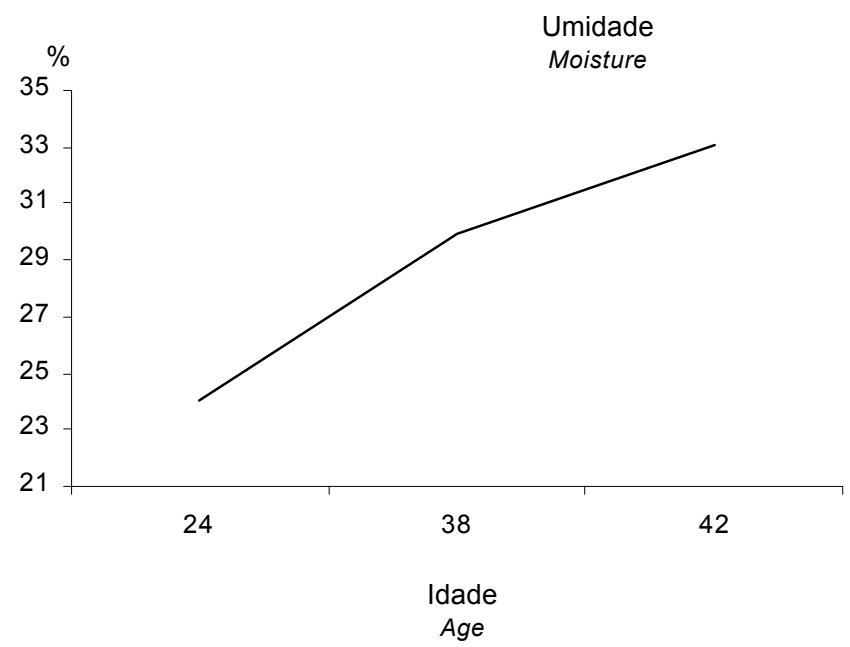

Figura 3 - Teor de umidade da cama de frango, em diferentes épocas de coleta.

Figure 3 - Moisture content of broiler litter in different periods of breeding. 
quadrático $(\mathrm{P}<0,05)$ da idade $(\mathrm{Y}=2,837-0,088 \times \mathrm{id}+$ $\left.0,0014 \times \mathrm{id}^{2}\right)$. Na Figura 5, pode ser observado o comportamento do efeito de idade sobre o teor de nitrogênio solúvel na cama aviária. Diferentemente do esperado, observa-se pequena redução no teor de nitrogênio solúvel aos 38 dias $(0,02$ g, aproximadamente) em relação ao teor aos 24 dias, com um posterior aumento aos 42 dias de idade.

Para o nitrato, observou-se efeito quadrático significativo $(\mathrm{P}<0,05)$ daidade $\left(\mathrm{Y}=15,23+4,57 \times \mathrm{id}-0,064 \times \mathrm{id}^{2}\right)$. Na Figura 6, pode-se observar que o maior teor de nitrato na cama ocorreu quando os animais estavam

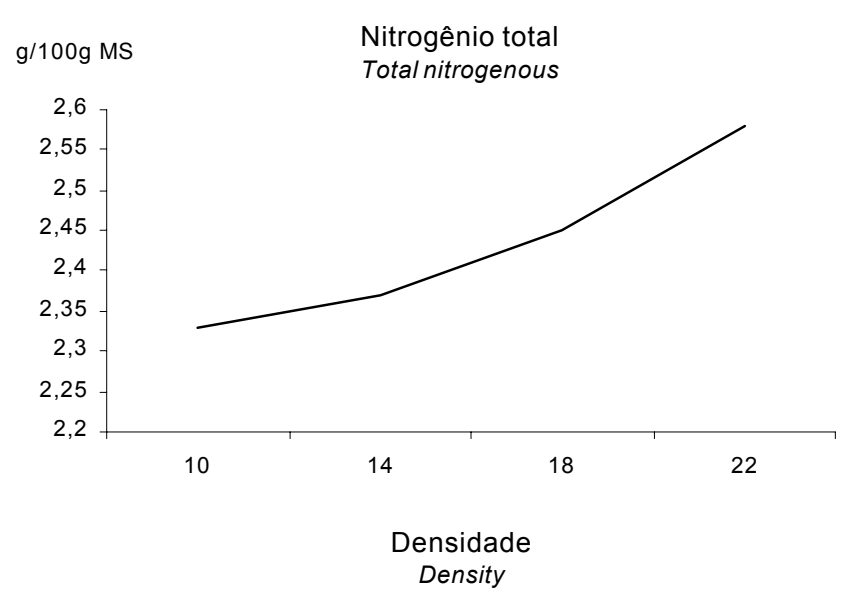

Figura 4 - Quantidade de nitrogênio total na cama de frango, em diferentes densidades de criação.

Figure 4 - Amount of total nitrogenous in the broiler litter in different stocking densities.

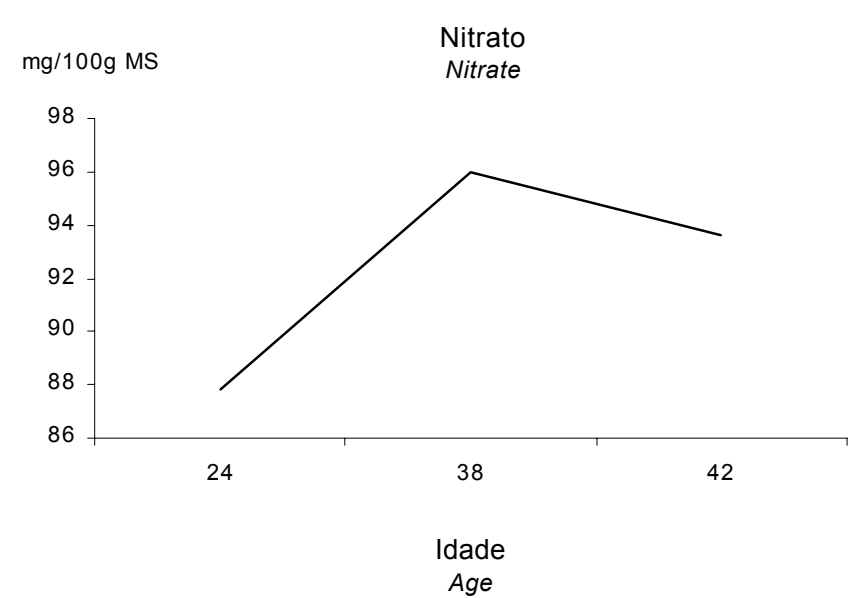

Figura 6 - Quantidade de nitrato na cama de frango, em diferentes épocas de coleta.

Figure 6 - Amount of nitrate in the broiler litter in different periods of breeding. com 38 dias de idade, havendo decréscimo do teor aos 42 dias. Também houve efeito significativo $(\mathrm{P}<0,01)$ da interação densidade $X$ sexo. A análise do efeito da densidade para cada sexo demonstrou não ter havido efeito significativo linear nem quadrático desta variável sobre o teor de nitrato, em ambos os sexos. $\mathrm{Na}$ Figura 7, pode ser observado o comportamento da densidade sobre o teor de nitrato para as fêmeas e machos. Verifica-se que a cama utilizada pelas fêmeas apresentou maior teor de nitrato para as densidades mais baixas ( 10 e 14 aves $/ \mathrm{m}^{2}$ ) e para a densidade mais alta $\left(22\right.$ aves $\left./ \mathrm{m}^{2}\right)$. Já para a densidade de 18 aves $/ \mathrm{m}^{2}$,

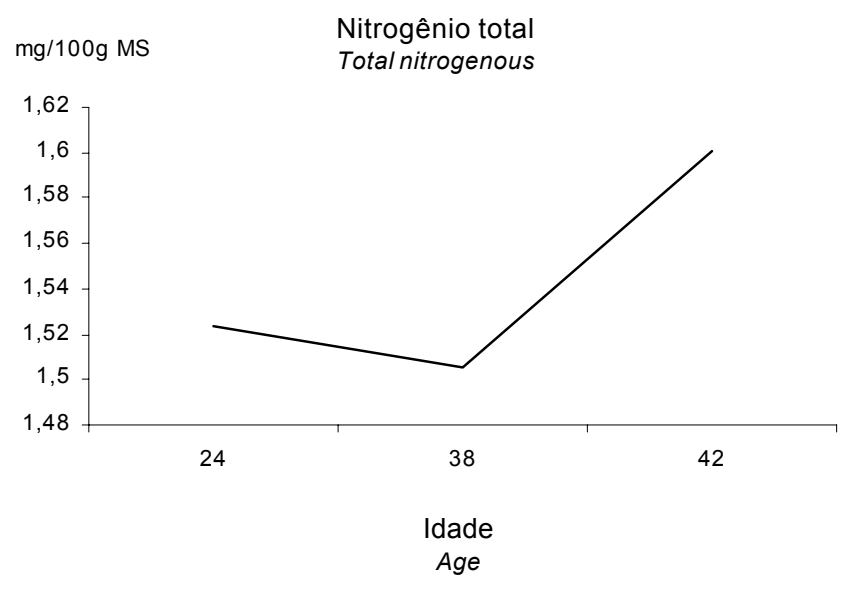

Figura 5 - Quantidade de nitrogênio solúvel na cama de frango, em diferentes épocas de coleta.

Figure 5 - Amount of soluble nitrogenous in the broiler litter in different periods of breeding.

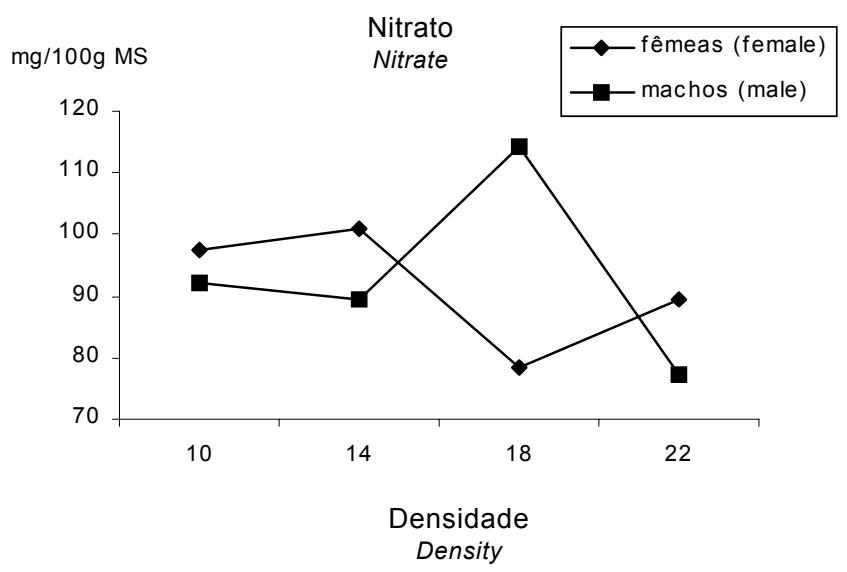

Figura 7 - Quantidade de nitrato na cama de frango para machos e fêmeas, em diferentes densidades de criação.

Figure 7 - Amount of nitrate in the broiler litter for males and females in different stocking densities.

R. Bras. Zootec., v.31, n.4, p.1795-1802, 2002 
a cama dos machos apresentou um teor de nitrato bem maior que a das fêmeas.

Para o teor de carboidratos redutores verificaram-se comportamentos distintos para o efeito de densidade nas três idades de coleta da cama (interação densidade $\mathrm{x}$ idade, significativa a nível de $1 \%$ ) e nos dois sexos (interação densidade $\mathrm{x}$ sexo significativa, em nível de 5\%). Observou-se efeito quadrático significativo $(\mathrm{P}<0,01)$ da densidade sobre o teor de carboidratos redutores para a idade de 24 dias $\left(\mathrm{Y}=1,171-0,075 \times\right.$ dens $+0,002 \times$ dens $\left.^{2}\right)$. A análise da Figura 8 revela que, para essa idade, houve redução do teor de carboidratos com o aumento da densidade. Esta redução também pode ser observada para a idade de 42 dias, embora esta tenha sido linear

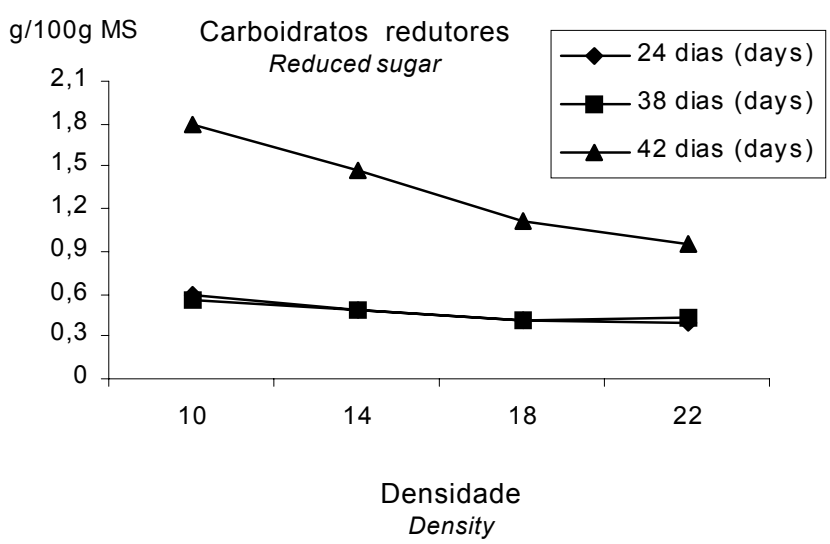

Figura 8 - Quantidade de carboidratos redutores na cama de frango, em diferentes épocas de coleta e densidades de criação.

Figure 8 - Amount of reduced sugar in the broiler litter in different periods of breeding and stocking densities.

na cama, nas densidades mais elevadas e no período final de criação, cuja conseqüência direta é um maior consumo de carboidratos pelos microrganismos.

\section{Conclusões}

O aumento da densidade e da época de amostragem induziu aumentos da quantidade de amônia liberada, do teor de umidade e dos teores de nitrogênio total e de nitrogênio solúvel, bem como a diminuição do teor de carboidratos redutores da cama das aves.
$(\mathrm{P}<0,01)$ ao longo das diferentes densidades $(\mathrm{Y}=2,472-0,071 \times$ dens $)$. Já para a idade de 38 dias, observa-se que praticamente não houve alteração do teor de carboidratos com o aumento da densidade.

Na Figura 9, pode-se observar que tanto para as fêmeas quanto para os machos houve tendência de redução do teor de carboidratos com o aumento da densidade. Para as fêmeas, verificou-se efeito linear significativo $(\mathrm{P}<0,05)$ da densidade sobre o teor de carboidratos redutores $(\mathrm{Y}=1,444-0,041$ $\times$ dens.), sendo que, para os machos, esta redução não foi linear $(\mathrm{Y}=1,349-0,055 \times$ dens. $+0,001 \times$ dens. ${ }^{2}$ ). A redução na quantidade de carboidratos redutores, observada nas Figuras 8 e 9, pode estar relacionada com uma maior atividade bacteriológica

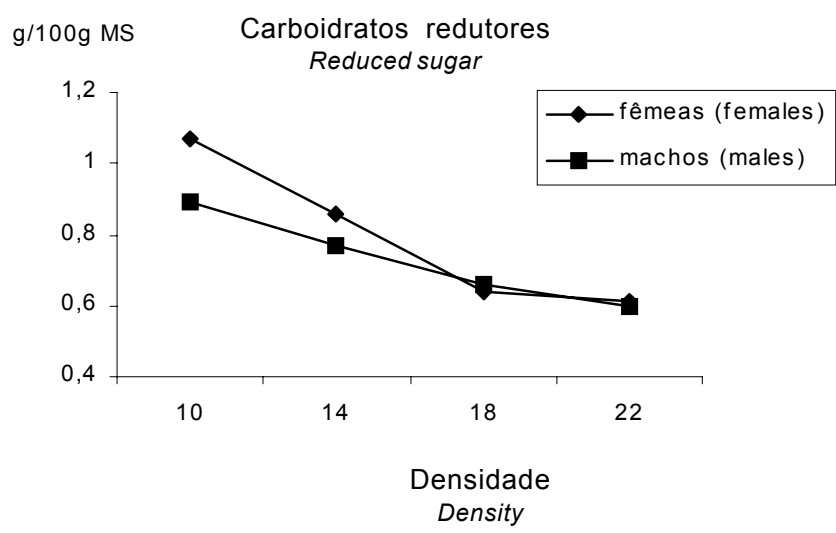

Figura 9 - Quantidade de carboidratos redutores na cama de frango para machos e fêmeas, em diferentes densidades de criação.

Figure 9 - Amount of reduced sugar in the broiler litter for males and females in different stocking densities.

O sexo das aves não influenciou as variáveis analisadas.

Os resultados obtidos sugerem a necessidade de um controle rigoroso da amônia no ar dos galpões, principalmente em densidades elevadas e no período final de criação, haja vista a maior liberação deste gás pela cama aviária nestas situações.

Para que medidas de controle possam ser tomadas, torna-se determinante o monitoramento dos níveis de amônia no ar dos galpões. Um método simples e acessível para a quantificação desses níveis pode ser observado em Hernandes \& Cazetta (2001). 


\section{Literatura Citada}

ASSOCIATION OF OFFICIAL ANALITICAL CHEMISTS AOAC. Official methods of analysis. 11.ed. Washington, D.C., 1970. 1015p.

ATTAR, A.J.; BRAKE, J. An economic analysis of the effects of ammonia and its control in broiler houses. Poultry Science, v.68, p.167, 1989. (supplement 1)

BELYAVIN, C. Actions in the poultry house can affect internal and external environments. World - Poultry, v.8, n.5, p.2425, 1992.

CABRERA, M.L.; CHIANG, S.C. Water content effect on denitrification and ammonia volatilization in poultry litter. Soil Science Society of American Journal, v.58, p.811816, 1994.

CATALDO, D.A.; HAROON, M.; SCHRADER, L.E. et al. Rapid colorimetric determination of nitrate in plant tissue by nitration of salicilic acid. Communication Soil Science \& Plant Analysis, v.6, p.71-80, 1975.

FALEIROS, R.R.S.; KANESIRO, M.A.B.; CAZETTA, J.O. Redução do nitrato em sorgo (Sorghun bicolor L. Moench) e labe labe (Dolichos lablad L.) cultivados isoladamente ou em culturas intercaladas. Revista de Agricultura, v.63, p.315-328, 1988.

GRAÇAS, A.S.; FONSECA, J.B.; SOARES, P.R. et al. Densidade populacional de frangos de corte em diferentes épocas do ano. Revista Brasileira de Zootecnia, v.19, p.186-196, 1990.

HARTUNG ,T.E. Floor space for broilers. Poultry Science, v.34, p.1200, 1955.

HERNANDES; R.; CAZETTA, J.O. Método simples e acessível para determinar amônia liberada pela cama aviária. Revista Brasileira de Zootecnia, v.30, n.3, p.824-829, 2001.

JOHNSON, R.W.; CURTIS, S.E.; SHANKS, R.D. Effects on chick performance of ammonia and heat stressors in various combination sequences. Poultry Science, v.70, p.11321137, 1991.

KUBENA, L.F.; REECE, F.N.; MAY, J.D. Nutritive properties of broiler excreta as influenced by environmental temperature, collection interval, age of broilers and diet. Poultry Science, v.52, p.1700-1703, 1973.
LIGERO, F.; LIUCH, C.; HERVAS, A. et al. Effect of nodulation on the expression of nitrate reductase activity in pea cultivars. New Phytologist, v.107, n.1, p.53-61, 1987.

MADELIN, T.M.; WATHES, C.M. Air hygiene in a broiler house: comparison of deep litter with raised netting floors. British Poultry Science, v.30, p.23-37, 1989.

MILLER, G. L. Use of dinitrosalicylic acid reagent for determination of reducing sugar. Analytical Chemistry, v.31, p.426-428, 1959.

MORENG, R.E.; ENOS, H.L.; BUSS, E.G. et al. The relationship of floor to factors influencing broiler growth. Poultry Science, v.40, p.1039- 1044, 1961.

OLIVEIRA, M.D.S.; VIEIRA, P.F.; SAMPAIO, A.A.M. Efeito do tempo de estocagem sobre a composição bromatológica da cama de frango. Revista Brasileira de Zootecnia, v. 17, n.2, p.115-119, 1988.

PARKHURST, C.R.; WHITE, L.; HAGLER Jr., W.M. et al. Broiler performance comparisons of selected litter materials over time. Poultry Science, v.66, p.156-159, 1987.

SMACCHIA, A.; FAIENZA, H.; PIDELLO, A. Contribution to the agronomic evaluation of poultry wastes.1. Stability of the nitrogen content. Revista Argentina de Produccion Animal, v.4, n.8, p.781-788, 1984.

STANLEY, V.G.; KRUEGER, W.F. The effect of stocking density on commercial broilers performance. Poultry Science, v.60, p.1737-1738, 1981.

WEAVER Jr., W.D.; MEIJERHOF, R. The effect of different levels of relative humidity and air movement on litter conditions, ammonia levels, growth, and carcass quality for broiler chickens. Poultry Science, v.70, p.746-755, 1991.

Recebido em: 19/09/00

Aceito em: 07/05/02 